\title{
Expanding uses of building information modeling in life-cycle construction projects
}

\author{
Kerosuo Hannele, ${ }^{*}$ Miettinen Reijo, Mäki Tarja, Paavola Sami, Korpela Jenni and Rantala Teija \\ Institute of Behavioural Sciences, Center for Research on Activity, Development and Learning, University of \\ Helsinki, P.O. Box 9 (Siltavuorenpenger 3A), 00014 University of Helsinki, Finland
}

\begin{abstract}
BIM is targeted at providing information about the entire building and a complete set of design documents and data stored in an integrated database. In this paper, we study the use of BIM in two life-cycle construction projects in Kuopio, Finland during 2011. The analysis of uses of BIM and their main problems will constitute a foundation for an intervention. We will focus on the following questions: (1) How different partners use the composite BIM model? (2) What are the major contradictions or problems in the BIM use? The preliminary findings reported in this study show that BIM has been adopted quite generally to design use but the old ways of collaboration seem to prevail, especially between designers and between designers and building sites. BIM has provided new means and demands for collaboration but expansive uses of BIM for providing new interactive processes across professional fields have not much come true.
\end{abstract}

Keywords: building information modeling, activity theory, multi-partner project collaboration, design, construction

\section{Introduction}

Building Information Modeling (BIM) has become after the year 2000 a more and more widespread term for a new technology (3D models, combined objectrelated information, and integrated workflows) and as a new approach to construction projects. BIM is aimed at providing information about the entire building (in all life cycle phases) and a complete set of design information stored in an integrated database. BIM is not just technology but it is seen as a catalyst for deeper process and contractual changes in building industry requiring more integrated approach than before.

BIM is, however, a "moving target" something that tends constantly to change and develop [9]. Also the term itself is subject to variation and different interpretations. BIM is a "generic technology" that in principle allows many benefits, like more efficiency in construction, less mistakes, more accurate and upto-date information, more illustrative and accessible exposition of the building and its characteristics to all stakeholders [2, pp. 19-26]. Like in the case of all generic technologies, the full realization of these possibilities, however, takes decades because of the de- velopment of complementary technologies (various software), the needed changes in social organization of construction (division of labor and collaboration in the construction process) as well as in regulations and economic contracts. And still, it is not sure how and to what extent the potentialities take place.

In this paper, we study the use of BIM in two lifecycle construction projects in Kuopio, Finland during 2011. The analysis of uses of BIM and their main problems will constitute a foundation for an intervention in which a zone of proximal development for the BIM use in the life cycle projects in question will be developed. In this paper results of the preliminary analyses will be shown. We will focus on the following questions:

1) How different partners use the composite BIM model?

2) What are the major contradictions or problems in the BIM use?

A life-cycle project is a novel contract method in which one party is responsible for the project planning and management, design, construction and maintenance for a long time (even 25 years) and requires a more integrated approach than traditional construction projects. The client defines the project's

\footnotetext{
* Corresponding author: Dr. Hannele Kerosuo. Institute of Behavioural Sciences, Center for Research on Activity, Development and Learning, University of Helsinki, P.O. Box 9 (Siltavuorenpenger 3A), 00014 University of Helsinki, Finland. Tel. +358 919144275 , Fax +358 9191 44579. E-mail: hannele.kerosuo@helsinki.fi.
} 
functional and quality requirements as well as the desired end result, but gives the service provider the freedom to choose the technical solutions and service practices. In that kind of a life-cycle model, the service provider can add value by developing the building's features, selecting sustainable and long-term economical solutions and sustaining high standard of service during the operation phase.

\section{Theoretical approach of the study}

We are using cultural-historical activity theory, CHAT [4], Charlotta Perez's theory of the structure of technological revolutions [10], as well as Morgan and Morrison's philosophy of modeling [9]. CHAT and expansive learning focus on the change of the object of joined activity and remediation of activity. Compared to traditional construction projects lifecycle projects change the object of the construction activity (i.e. how the whole process is organized).

Charlotta Perez's theory problematizes the temporal dynamics between technological change and institutional/organizational change. One of the themes in evolutionary economics of innovations is the different temporal dynamics of the development of technology and social and institutional structures $[10, p$. 5]. The new technologies are brought to the organizational structures developed in the prior phase of production. The full deployment of the possibilities of the new technology will require the reorganization of organizational and institutional structures.

This duality or incompatibility of technological and organizational change is visible also in the definitions of BIM presented by the construction engineering literature. We can make a distinction between definitions emphasizing 1) the role and features of the new technology, or a development of a family of BIM software based on it, 2) the new approach to a building process by using BIM in construction projects. BIM is connected usually to more integrated collaborative processes also when it comes to contractual relationships (in a mature form realized in "Integrated Project Delivery") [11]

An example of the first, general technologically oriented definition is that "a building information model (in theory) provides a single, logical, consistent source for all information associated with the building" [7]. Eastman's [3] definition ties this general characterization to the development of a family of parametric modelers: "An essential capability of all the BIM (Building Information Model) design tools is their support of parametric modeling. Revit ${ }^{\circledR}$, ArchiCad $\AA$, Bentley Architecture, Digital Project $\AA$, and Vector-works ${ }^{\circledR}$ are all parametric modelers. Parametric modeling matured in the $1980 \mathrm{~s}$ and $90 \mathrm{~s}$ through intense industrial development and university research. The basic idea is that $2 \mathrm{D}$ and $3 \mathrm{D}$ solid object shapes can be defined according to parameters, some of which are user-defined values and others relative to other shapes."

Another way of defining BIM is to see it first of all as a toolkit of the construction project management, made possible by the new technology. In these definitions, BIM provides ways of handling the data of the whole construction process, not only on the building as such. "A building information model is a project simulation consisting of 3D models of the project components with links to all the required information connected with the project's planning, construction or operation, and decommissioning" [8, p. 28]. According to Eastman "BIM is fundamentally different way of creating, using, and sharing building lifecycle data." [2, p. 16]

These definitions directly refer to the social organization of the BIM use, that is, the exchange and sharing of information between the project members and stakeholders. Also these definitions are often connected to technology, that is, to the fact that "single, logical repository of information" is something that in principle is achievable because of the technology. However, Howard and Björk [6] conclude based on the study of the uses of BIM and possibility of an integrated model [pp. 273-274] "The single building model is seen as cumbersome by some and will need to be used in conjunction with other forms of data ... The single BIM has been a holy grail but it is doubtful whether there is a will to achieve it."

Howell and Batcheler [7] call the technological promise of a single building information model as "the utopia of BIM." The technological definition of BIM (3D plus object-related parametric information integrated into one model for all stakeholders) is a vision of possibilities of pure technology. It is, however, abstracted out of the social and practical conditions of its realization. The realization of the utopia is dependent, among others, on the availability and compatibility of families of relevant software, on standardization of information used in models, on the compatibility of the models and others tools traditionally used by various professional groups, forms of collaboration and interaction, regulations, contracts as well as economic interests of the participants.

The models as representations and means of simulating complex systems and phenomena have exten- 
sively been discussed in the philosophy and in empirical studies of the modeling work. In philosophy of modeling, the problem has traditionally been the connection of model to theories, empirical data, and experimentation. The elements included in the models are derived from theory and their relationships are also based on understanding of the phenomena included. Because of the rapid increase in the calculating capacity of computers and development of software, computer-based modeling has become an independent powerful tool of representing, simulating and experimenting with complex systems. Although, the BIM models are first of all design and project management tools, the emergent possibilities of simulating the behavior of some aspects of buildings (like energy consumption) are more and more relevant.

In the philosophy of modeling, several authors have suggested that the nature of modeling could best be understood by analyzing concretely how models are actually used instead of analyzing their potential features only [9]. We also find this approach suitable for studying the uses of BIM. We agree with the authors that understanding BIM is a gradual and evolutionary process of utilizing various BIM models for specific purposes in different phases of construction process. Based on the evolutionary theory of innovations and activity theory, the new tools are always brought to existing (old) organizational structures and used simultaneously and interactively with traditional tools as new elements that transform the established practices and skills. The constant dynamics of solving contradictions between old and new practices and means is a pervasive feature of the development.

Morgan [9] theorizes the various functions of models in research work. This theorizing can be used in the analysis of the uses of BIM in the design work. Together the theory of expansive learning and Morgan's theory provide a framework for the analysis of the expanding uses of BIM. The criteria of expansion are the range and complexity of the phenomena and interrelationships simulated in its multi-partner collaborative use, organizational forms, and quality of interaction in collaborative use.

\section{Data and methods}

The data of the study was gathered as a part of Built Environment Process Re-engineering -research programme (funded by TEKES, the Finnish Funding Agency for Technology and Innovation) and its ModelNova-workpackage (http://www.rym.fi/en/programs/builtenvironmentpro cessreengineeringpre/). The research program started in November 2010, and will continue until December 2013. The concrete case of the study is a life cycle construction project in Kuopio, Finland. The phenomena to be studied include the possibilities that emerge from BIM utilization, the realization of the possibilities and possible obstacles of BIM-use, current working methods, changing roles of various parties, and the needs and opportunities for change from their perspectives. New processes and practices as well as new forms of cooperation will be developed during the research. The developed practices and processes will be piloted and the research data will be collected in the piloting phase.

The data analyzed for this paper is based on interviews of the key partners in the life-cycle construction project $(\mathrm{N}=25)$. Three members of the research group of six researchers interviewed the key partners involved in the construction project. The key partners were users, clients, developers, investors, contractors, architects, special designers, supervisors, and other authorities. The interviews were conducted in a halfstructured manner, focusing on the themes presented but also allowing room for adapting to emerging topics. The questions related to this study were: For what purposes have you used BIM in the projects? Give concrete examples. If not, why? What are the possible problems or obstacles to BIM use?

All interviews were conducted between February and March 2011 in Helsinki and Kuopio, Finland. Each interview lasted approximately one hour. The data is transcribed verbatim. Atlas.ti program was used in the analysis of interviews. The coded segments of the category of BIM use occurred 88 times in the transcribed interviews. These segments are further analyzed in this paper. In the analysis, the coded segments are divided into categories according to the phase of the construction process. The phases involve: design and planning, construction, and maintenance of buildings.

\section{Findings}

\subsection{Use of BIM in the construction project}

First, in the design and planning phase of the construction project different professional groups used BIM in architectural design, HPAC (heating, plumbing, air-conditioning) and electricity planning, and structural engineering. Architects explained that 
they use BIM-based modeling (ArchiCad) in most of their design work. However, they felt that the amount of their design work had increased as their collaborators asked them to design for other purposes than what they felt was the task of architecture and design. For instance, architects were asked to add information to BIM models for the purposes of cost accounting, and structural planning. Information is also needed in quantity surveys of building materials such as façade covers, number of windows, doors etc.

Architect: "We provide knowledge to others in a way that is not related to architecture and design but to the production of technical knowledge."

HPAC engineers used BIM in various tasks. For instance, BIM was used in the comparison of window choices, in choices of solar shading, and energy consumption.

HPAC engineer: "We have simulated the realization of internal conditions, compared different choices for windows and solar shading in order to reach the required conditions. And then also the energy consumption in the building because we have these goals and it is also important in the life cycle of the building that we get the energy consumption clamped down."

Structural engineers told that they use BIM in planning of structures and elements. Structural engineers take plans modeled by architects in ArchiCad and convert them into objects they can use with their own software (called TEKLA). However, an engineer explained that he did not succeed to convert all necessary objects he was working on in the focused construction project. The conversion of pillars was only successful from ArchiCad to Tekla software.

Second, the collaborative use of BIM in the design and planning involved also energy calculation and simulation. In the interviews, the HPAC engineers explained that energy calculation and simulation models were used collaboratively with the architects and project managers in the planning meetings. Altogether, collaborative use of BIM is problematic and under development in construction projects. For instance, a plan review and clash detection of different plans that are mentioned in research literature as benefits of BIM use [e.g., 8] were not yet adopted to use very effectively in our case example (this is described more in section 4.2).

Third, there were few examples of a quite basic use of BIM in collaboration with partners that were not directly involved in the design and planning of the buildings. For instance, BIM models were used in the visualizations of buildings in customer collaboration. The construction company in question used a composite BIM model for introducing their future school for the pupils.

Fourth, there were expressions of non-use of BIM in the interviews. The supervisor did not use BIM modeling himself being perhaps near retirement.

Supervisor: "I am not using [BIM]. I try to keep to the traditional supervision and I do not believe that I will take that at this stage."

Representatives of the customer organization did not use BIM model either. They did not have access to the project bank where BIM models created by different professionals were saved for the collaborative use.

The most important uses referred by the interviews to the construction phase related to the quantity survey, new ways of scheduling production, planning and management, calls for bids and procurements, control of costs, and instruction of workers at the building site.

The site engineer told in the interview that BIM is used in the quantity survey that is needed for various tasks at the building site. New ways of scheduling production, planning, and management is one of the tasks in which quantities are needed. The use of BIM model (ArchiCad) was an important tool for taking out the quantities needed in scheduling. What was new in that case was that the quantities could be obtained from the model instead of lists as it was done before BIM models. However, it is not yet possible to manage the entire process of scheduling with the modeling tools.

Site Engineer: "In practice, we get the quantities from ArchiCad model and then import them to Control [Vico Control] software, in fact in an excel chart, the chart can then be sucked in that Control quite easily."

Site engineers also used the BIM model to call for bids and procurements.

Site engineer: "We send pictures of the model from every angle, showing how the architect has thought to do things and what has been used there." 
Information from the modeling was also used for controlling the costs. Keeping track of the completion and billing was one of the site engineers' uses of modeling.

Site engineer: "I just put that into the model and you get the quantities from the model, so that the guys don't need to measure it."

Instruction of workers at the building site was one additional task that the site engineers used the model during construction.

Site engineer: "We got guys queuing for the machine there. All the electricians, plumbers and HPAC are waiting because they have to check this or that."

Although, the findings above show that the use of BIM modeling is very useful in the focused building sites, the findings cannot be generalized yet. The use of BIM is still a new thing and the engineers interviewed in the study can be considered first users at the building sites.

We did not get much evidence on the use of BIM modeling during the phase of building maintenance. The maintenance of buildings was mentioned in three interviews. The interviewees told that they did not know how BIM modeling could be used during maintenance of buildings.

Project manager: "Using modeling to maintenance is a thing that is in fact actually being inspected at the moment. We do not have any answers to that yet. It needs to be connected to those tools that the maintenance staff is using but it is not yet possible"

Maintenance manager: "Modeling is originally deriving from the needs of production, now it is thought that it could be used in the maintenance."

Site Engineer: "We have been in contact with the maintenance manager during the building phase but we have no exchanges on the use of models during maintenance."

\subsection{Major contradiction and problems in BIM use}

In the literature of BIM, it has been emphasized that one of the benefits of BIM is that it can be used in clash detection of designs and plans. Individual models of different professional groups can be combined into composite models with the help of BIM. Kymmell [8, p. 38] notes that "the parts of the composite model can be coordinated so that any existing conflicts (multiple objects occupying the same space) can be found and resolved. This process is referred as clash detection." The clash detection is considered a critical task in construction processes, especially, when mechanical, electrical and plumbing designs are fitted together in plans and design.

In our Finnish case, the information modeling expert created composite model with the help of a special software (Solibri). All the designs and plans of the researched project are saved in the project bank and combined in the Solibri model. One of the functions of Solibri is that the clash detection can be conducted technically with the program. This is one of the tasks of the information modeling expert. However, it was unclear what happened to the clash detection after it was technically done. In principle, it is one of the responsibilities of the architect to secure the combination of different designs.

Architect: "It is the information modeling expert who creates the composite model because we do not have software to do that. The software is quite expensive and we have agreed that the expert conducts it [the clash detection]. But in a way it is also a little our task."

Traditionally, the plan review and the clash detection have been conducted at building sites during construction processes. Now, the conflicting plans can be checked during the design and planning phase. However, this not the case! The site engineer explained that they are still doing the plan review at the building site but they can use BIM models to detect the conflicts.

Site engineer: "We are doing all inspections on that walkway there, so that there's nothing sticking down from the ceiling, and we've had an air vent be several meters too long or the roof drains are a meter too high. You can get on it right away, nobody would see this stuff from a 2 D plan."

Clash detection is an example of a contradiction between old and new ways of working. The new BIM technology is adopted into old collaboration practices and ways of working, and its benefits are then limited. 


\section{Discussion}

In the literature of BIM various (potential) benefits of BIM technology are often listed [2, pp. 19-26]. A most "mature" use of BIM is seen to involve collaboratively created, shared, and maintained models across project lifecycle [11]. In practice there are many social and institutional obstacles to these more advanced uses, which would require new ways of organizing collaborative processes. The preliminary findings reported in this study show that BIM has been adopted quite generally to the design use but the old ways of collaboration seem to prevail, especially between designers and between designers and building sites. BIM has provided new means and demands for collaboration but expansive uses of BIM for providing new interactive processes across professional fields have not much come true.

One limitation of this pre-study is that it is based mainly on interviews. Interviews are not sufficient means of studying the real use of BIM and related problems, since the actors easily tell their opinions and visions that do not necessarily corresponds to the actual reality or help in making sense the conditions of implementing the new technologies. In the next phase of the project, we are focusing on observing the use of BIM both in design and planning phase, and in construction site.

We presume that the implementation of BIM has a potential to develop from the uses of specific BIM software by the project members towards collaborative uses (such as clash analysis) of a composite model. The nature of BIM as a generic technology opens constantly new uses that, however, require workable software tools, new ways to organize the social interaction as well as to the other instrumentalities used by the practitioners. In this approach solutions are sought in which the individual designers and users can improve their practices by using BIM, and on the other hand, the form of collaborative uses of BIMs. The concrete steps in such an extension of BIM uses must be grounded on the understanding of present uses of BIMs (and their relationship to uses of non-BIM tools) and their problems.

\section{References}

[1] V. Bazjanac and A. Kiviniemi. (2007). Reduction, simplification, translation and interpretation in the exchange of model data, in D. Rebolj, ed., Proceedings of $24^{\text {th }}$ W78 Conference Maribor 2007, "Bringing ITC knowledge to work". University of Maribor \& CIB \& EGICE, 2007, $163-168$.

[2] C. Eastman, P. Teicholz, R. Sacks and K. Liston. BIM Handbook ( $2^{\text {nd }}$ Edition) A guide to building information modeling for owners, managers, designers, engineers and contractors, John Wiley \& Sons, New Jersey, 2011.

[3] C. Eastman, University and industry research in support of $\mathrm{BIM}$, in Report on integrated practice, $2 / 11$, released during the 2006 AIA National Convention, Los Angeles, 2006.

[4] Y. Engeström, R. Miettinen and R-L. Punamäki. eds., Perspectives on Activity Theory, Cambridge University Press, U.K: Cambridge, 1999.

[5] C. Freeman and F. Louçã. As Time Goes By: From the Industrial Revolutions to the Information Revolution, Oxford University Press, Oxford, 2001.

[6] R. Howard and B. C. Björk, Building information modeling, Expert's views on standardization and industry deployment, Advances Engineering Informatics 22 (2008), 271-280.

[7] I. Howell and B. Batcheler, Building Information Modeling Two Years Later - Huge Potential, Some Success and Several Limitations, The Laiserin Letter, May 2005.

[8] W. Kymell, Building information modeling. Planning and managing construction projects with $4 \mathrm{D}$ CAD and simulations., McGrawHill,New York, 2008.

[9] M. Morgan and M. Morrison, eds., Models as Mediators. Perspectives on Natural and Social Science. Cambridge: University Press, Cambridge, 1999.

[10] C. Perez,.Technological Revolution and Financial Capital: The Dynamics of Bubbles and Golden Ages, Edward Elgar Cheltenham, 2002.

[11] B. Succar, Building information modeling framework: A research and delivery foundation for industry stakeholders, Automation in Construction, 18 (2009), 357-375. 